\title{
Evaluasi Indeks Slagging, Fouling Pada Boiler Batubara Jenis Lignit dan Bituminus
}

\author{
Ika Yuliyani*, Indriyani, Muna Indrayana \\ Jurusan Teknik Konversi Energi, Politeknik Negeri Bandung \\ Jalan Gegerkalong Hilir, Ciwaruga, Parongpong, Kabupaten Bandung Barat, Jawa Barat 40559 \\ *Email: ika.yuliyani@polban.ac.id
}

Diterima: 02-02-2021; Direvisi: 02-11-2021; Dipublikasi: 30-12-2021

\begin{abstract}
Abstrak
Batubara saat ini merupakan salah satu jenis bahan bakar yang banyak digunakan padaPLTU. Pada proses pembakaran batubara selain menghasilkan panas juga menghasilkan partikulat abu yang terbawa bersama gas panas. Partikulat abu batubara memiliki kemampuan untuk menempel pada dinding boiler dan kemampuan menempelnya abu ini terutama dipengaruhi oleh suhu melebur abu (ash fusion temperature, AFT) dan unsur - unsur dalam abu.Ada 2 jenis fenomena menepelnya abu batubara pada dinding boiler, yaitu slagging dan fouling. Hal ini akan berdampak pada penggunaan batubara menjadi lebih banyak dan meningkatkan pekerjaan pemeliharaan boiler. Metode evaluasi indeks slagging dan fouling mengunakan analisa karakteristik batubara melalui perhitungan indeks slagging dan fouling. Analisa karakteristik batubara dengan menggunakan analisis komposisi abu (SiO2, Al2O3, Fe2O-3, $\mathrm{CaO}, \mathrm{MgO}, \mathrm{K} 2 \mathrm{O}, \mathrm{Na} 2 \mathrm{O}$, $\mathrm{TiO} 2, \mathrm{MnO} 2$ ), ash fusion temperature, analisis proksimat (Kadar air, abu, zar terbang, dan karbon padat), analisis ultimat(C, H, S, N), dan penentuan nilai kalor batubara. Penelitian ini menggunakan metode perhitungan dengan menggunakan data analisa dari batubara,yaitu analisa proksimate, ultimate dan ash fusion temperature. Berdasarkan evaluasi dan analisa yang diperoleh bahwa abu jenis bituminous dengan kandungan unsur $\mathrm{Fe} 2 \mathrm{O} 3$ memiliki pengaruh pada indeks pembentukan slagging dengan hasil indeks slagging lebih rendah, dan abu jenis lignit dengan unsure kandungan $\mathrm{CaO}$ dan $\mathrm{MgO}$ sangat mempengaruhi besar nilai indeks pembentukan slagging dengan hasil indeks slagging lebih tinggi jika dibandingkan dengan batubara jenis bituminus. Begitujuga halnya dengan kandungan $\mathrm{Na} 2 \mathrm{O}$ pada abu bituminous dan lignit menjadi unsur yang berpengaruh ini selain indeks pembentukan fouling.
\end{abstract}

Kata kunci: Batubara, pembakaran, Indeks Slagging, Indeks Fouling

\begin{abstract}
Coal is currently one type of fuel that is widely used in power plants. In the process of burning coal, in addition to producing heat, it also produces particulate ash which is carried away with hot gases. Coal ash particulates have the ability to stick to the boiler wall and the ability to stick to the ash is mainly influenced by the ash fusion temperature (AFT) and the elements in the ash. . This will have an impact on the use of coal to be more and increase boiler maintenance work. The method of evaluating the slagging and fouling index uses the analysis of coal characteristics through the calculation of the slagging and fouling index. Analysis of coal characteristics using ash composition analysis ( $\mathrm{SiO} 2, \mathrm{Al2O}$, $\mathrm{Fe} 2 \mathrm{O} 3, \mathrm{CaO}, \mathrm{MgO}, \mathrm{K} 2 \mathrm{O}, \mathrm{Na2O}$, TiO2, MnO2), ash fusion temperature, proximate analysis (moisture content, ash, volatile matter, and solid carbon), ultimate analysis $(C, H, S, N)$, and determination of the calorific value of coal. This study uses a calculation method using analytical data from coal, namely the analysis of proximate, ultimate and ash fusion temperature. Based on the evaluation and analysis, it was found that bituminous ash with $\mathrm{Fe} 2 \mathrm{O} 3$ content had an influence on the slagging formation index with a lower slagging index result, and lignite ash with $\mathrm{CaO}$ and $\mathrm{MgO}$ content greatly influenced the value of the slagging formation index with a higher slagging index result. when compared to bituminous coal. Likewise, the content of $\mathrm{Na2O}$ in bituminous ash and lignite is an influential element in addition to the index of fouling formation.
\end{abstract}

Keywords: Coal, combustion, Slagging Index, Fouling Index

\section{Pendahuluan}

Saat ini pemakaian bahan bakar batubara pada boiler PLTU paling banyak digunakan, karena ketersediaanya yang masih mampu untuk 50 tahun kedepan. Selain itu batubara dengan kuantitas yang besar mampu menghasilkan panas pembakaran yang dapat menghasilkan uap bertekanan dan bertemperatur tinggi yang mampu menghasilkan daya listrik yang cukup besar pada sebuah PLTU.Hampir semua PLTU dengan kapasitas daya pembangkitan yang besar menggunakan bahan bakar batubara. Akan tetapi pemakaian batubara selain menghasilkan panas pada proses 
Ika Yuliyani dkk /Jurnal Rekayasa Mesin

p-ISSN: 1411-6863, e-ISSN: 2540-7678

Vol.16|No.3|299-310|Desember|2021

pembakarannya, juga menghasilkan partikulat abu. Partikulat-partikulat abu tersebut dapat menyebabkan terjadinya slagging dan fouling pada dinding atau tube-tube boiler. Fenomena terjadinya slagging dan fouling ini biasanya tidak sampai pada tingkat yang mengganggu performa dinding penghantar panas, karena adanya soot blower yang berfungsi untuk menghilangkan abu-abu yang menempel pada dinding dan tube boiler. Akan tetapi bila sebagian batubara yang dibakar tersebut memiliki suhu lebur abu (AFT) relative rendah dan berkadar lempung tinggi, maka abu yang menempel akan membentuk lapisan dan lama - kelamaan akan berkembang dan membentuk slagging dan fouling. Jika hal ini berlangsung terus, maka dapat menyebabkan turunnya kemampuan kerja dari boiler tersebut.

Terbentuknya slagging dan fouling pada dinding dan tube akan mempengaruhi proses perpindahan panas pada boiler, peningkatan konsumsi bahan bakar, dengan tentunya dapat menyebabkan turunnya efisiensi dari boiler. Pada kasus-kasus tertentu yang ekstrem dapat menyebabkan terjadinya pemadaman plant yang tidak terencana untuk proses penghilangan abu dan perbaikan pada boiler. Potensi pembentukan kecepatan slagging dan fouling dapat diketahui dari parameter nilai potensi slaggging dan foulingnya. Dari parameter slagging dan fouling, terdapat range yang menunjukan potensi terjadinya slagging dan fouling. Berikut adalah range potensi slagging dan fouling yang pernah diteliti oleh beberapa peneliti/ penulis sebelumnya:

Tabel 1. Potensi Slagging

\begin{tabular}{|c|c|c|c|c|c|}
\hline No & Penulis/Judul/tahun & Parameter & Indek & Potensi & \\
\hline 1 & $\begin{array}{l}\text { Jianbo li (2016), "effect of coal blending on ash fouling } \\
\text { and slagging in pulverized coal fired supercritical (SC) } \\
\text { and ultra-supercritical (UC) power planr," thesis } \\
\text { university of western australia, australia, 2016. }\end{array}$ & $\begin{array}{l}\text { Ash fusion } \\
\text { temperature } \\
\left({ }^{\circ} \mathrm{C}\right)\end{array}$ & $\begin{array}{l}>1343 \\
1232-1343 \\
1149-1232 \\
<1149\end{array}$ & $\begin{array}{l}\text { Rendah } \\
\text { Sedang } \\
\text { Tinggi } \\
\text { Parah }\end{array}$ & \\
\hline 2 & $\begin{array}{l}\text { Piotr (2013), The development of a slagging and fouling } \\
\text { predictive methodology for large scale pulverized boiler } \\
\text { fired with coal and biomass blend. Cardiff : thesis cardiff } \\
\text { university, } 2013 \text {. }\end{array}$ & $\mathrm{T} 250(\mathrm{oC})$ & $\begin{array}{l}>1400 \\
1245-1400 \\
1120-1245 \\
<1120\end{array}$ & $\begin{array}{l}\text { Rendah } \\
\text { Sedang } \\
\text { Tinggi } \\
\text { Parah }\end{array}$ & \\
\hline 3 & $\begin{array}{l}\text { Piotr (2013), The development of a slagging and fouling } \\
\text { predictive methodology for large scale pulverized boiler } \\
\text { fired with coal and biomass blend. Cardiff : thesis cardiff } \\
\text { university, } 2013\end{array}$ & $\begin{array}{l}\text { iron-calcium } \\
\text { ratio }\end{array}$ & $\begin{array}{l}<0,3 \quad \text { atau } \\
>3,0\end{array}$ & $\begin{array}{l}\text { Rendah } \\
\text { sedang }\end{array}$ & sampai \\
\hline
\end{tabular}

Tabel 2. Potensi Fouling

\begin{tabular}{lcccc}
\hline No & \multicolumn{1}{c}{ Penulis/Judul/Tahun } & Parameter & Indek & \multicolumn{1}{c}{ Potensi } \\
\hline 1 & Jianbo li (2016), "effect of coal blending on ash fouling & Kadar sodium & $<2,0$ & Rendah \\
& and slagging in pulverized coal fired supercritical (SC) & (khusus untuk & $2-6$ & Sedang \\
& and ultra-supercritical (UC) power planr," thesis & abu lignit)(\%) & $6-8$ & Tinggi \\
& university of western australia, australia, 2016. & & $>8$ & Parah
\end{tabular}


Ika Yuliyani dkk /Jurnal Rekayasa Mesin

p-ISSN: 1411-6863, e-ISSN: 2540-7678

Vol.16|No.3|299-310|Desember|2021

\begin{tabular}{lllll}
\hline No & Penulis/Judul/Tahun & Parameter & Indek & Potensi \\
\hline 2 & The Babcock and the wilcox & Faktor & $<0,2$ & Rendah \\
& & fouling & $0,2<\mathrm{Rf}<0,5 \quad$ Sedang \\
& (khusus untuk & $0,5<\mathrm{Rf}<1,0 \quad$ Tinggi & Parah \\
& abu & $1,0<\mathrm{Rf}$ & \\
& bituminus) & & \\
& & &
\end{tabular}

Dari tabel 1 potensi slagging pada tahun 2016 Jianbo li melakukan penelitian potensi slagging pada boiler PLTU berbahan bakar batu bara jenis medium rank, menggunakan metode Ash fusion temperatur hasilnya potensi kecepatan pembentukan slagging rendah dengan nilai datas 1343. Sedangkan potensi pembentukan slagging dengan metode T250 ditulis oleh Piotr (2013) pada disertasinya. Menghasilkan potensi kecepatan pembentukan slagging medium dengan nilai sedang menggunakan bahan bakar batubara jenis medium rank.

\section{Material dan metodologi}

\subsection{Klasifikasi batubara}

Klasifikasi Batubara berdasarkan proses pembentukan dan bentuk fisiknya batubara dibedakan menjadi:

1. Lignit / batubara muda

Batubara muda ini berwarna agak coklat dengan garis-garis yang nampak seperti kayu, karena maturitas organik nya rendah, batubara ini lebih lembut, unsur volatile nya tinggi dan nilai kalornya lebih rendah daripada jenis lainnya. Memiliki kandungan air yang besar bisa mencapai $45 \%$.

2. Subbituminus

Berwarna hitam kecoklat - coklatan atau hitam saja, bersifat homogen dengan permukaan halus, dan tidak nampak adanya lapisan -lapisan. Batubara ini menguap jika berkenaan dengan udara, jika ini terjadi, batubara akan retak dan bisa terbakar sendiri (spontaneous combustion).

3. Bituminus

Batubara ini yang bila dipanaskan akan menggumpal dan sulit dipecah. Berwarna hitam keabu-abuan. Batubara ini cocok dipakai untuk pembuatan gas. Batubara bituminus diklasifikasikan lagi menjadi bituminus volatileA,B dan C. Bituminus dengan volatile tinggi A, sebagianbesar bersifat homogen tanpa nampak butirbutir, tetapi beberapa menunjukkan lapisanlapisan jelas, bersifat keras dan kuat, dengansedikit retak-retak. Kandungan air, belerang dan kandungan abunya rendah dengan nilai kalor yang tinggi. Bituminus dengan voltile tinggi B,mempunyai susunan garis-garis sejajar(laminer) yang jelas. Bersifat keras dan Jurnal Power Plant ISSN No :2356-151347 tahan, retak-retak umumnya membentuk sudut 900 dan sejajar lapisan, karena itubongkahannya berbentuk kubus. Bituminus dengan volatile tinggi C,mempunyai struktur laminer yang jelas,keras, dan sangat kuat. Umumnya memiliki kandungan air, belerang dan abu yang tinggidan batubara ini dikenal dengan batubara yang mudah terbakar.

4. Antrasit

Batubara dengan kualitas yang paling baik. Bersifat keras dengan warna hitam mengkilat,homogen dengan tanpa ada tanda-tanda berlapis. Batubara jenis ini tidak mudah terbakar, untuk mempermudah pembakaran, umumnya digiling terlebih dahulu sebelum dibakar. 
Ika Yuliyani dkk /Jurnal Rekayasa Mesin

p-ISSN: 1411-6863, e-ISSN: 2540-7678

Vol.16|No.3|299-310|Desember|2021

\subsection{Slagging dan Faouling}

Slagging adalah fenomena menempelnya partikel abu batubara baik yang berbentuk padat maupun leburan, pada permukaan dinding penghantar panas yang terletak di zona gas pembakaran suhu tinggi (high temperature combustion gas zone), sebagai hasil dari proses pembakaran batubara. Khususnya pada dinding dekat ruang bakar dimana terjadinya perpindahan panas konveksi pada bagian outlet dari tungku (furnace), bila suhu gasnya melebihi temperatur melunak abu (ash softening temperature). (ash), zat terbang (volatile matter), dan kadar karbon (fixed carbon).

Fouling adalah fenomena menempel dan menumpuknya abu pada dinding terpat terjadinya perpindahan panas (super heater maupun re-heater) yang dipasang di lingkungan dimana suhu gas pada bagian belakang furnace lebih rendah dibandingkan suhu melunak abu (ash softening temperature).

Unsur yang paling berpengaruh pada penempelan abu ini adalah material basa terutama $\mathrm{Na}$, yang dalam hal ini adalah kadar Na2O. Bila kadar abu batubara banyak, kemudian unsur basa dalam abu juga banyak, ditambah kadar $\mathrm{Na} 2 \mathrm{O}$ yang tinggi, maka fouling akan mudah terjadi. Untuk slagging ini, karakteristiknya dapat dinilai dari suhu lebur abu (AFT) dan kondisi abu itu sendiri. Suhu lebur abu yang rendah akan memudahkan terjadinya slagging. Kemudian, diketahui pula bahwa bila rasio unsur alkali (Fe2O3, $\mathrm{CaO}, \mathrm{MgO}, \mathrm{Na} 2 \mathrm{O}, \mathrm{K} 2 \mathrm{O})$ terhadap unsur asam ( $\mathrm{SiO} 2, \mathrm{Al} 2 \mathrm{O} 3$, TiO2) meninggi, potensi timbulnya slagging juga meningkat.

Evaluasi karakteristik terjadinya indeks fouling juga sama dengan slagging, yaitu dinilai berdasarkan rasio unsur basa dan asam, serta kadar $\mathrm{Na} 2 \mathrm{O}$ di dalam abu. Jika nilai - nilai tadi tinggi, maka secara umum kecenderungan fouling juga meningkat. Metode yang digunakan pada penelitian ini adalah metode perhitungan dengan menggunakan evaluasi representatif untuk slangging dan fouling. Berikut metode evaluasi representatif slagging dan fouling.

\subsection{Metode evaluasi representatif slagging.}

Pada metode ini, penilaiannya akan berbeda sesuai dengan komposisi unsur pembentuk abu sebagaimana ditampilkan di bawah ini.

- Abu tipe bituminus

$\mathrm{CaO}+\mathrm{MgO}<\mathrm{Fe} 2 \mathrm{O} 3$.

- $\quad$ Abu tipe lignit

$\mathrm{CaO}+\mathrm{MgO}>\mathrm{Fe} 2 \mathrm{O} 3$.

a) Abu tipe bituminus

Pada tipe ini, karakteristik slagging ditentukan berdasarkan perhitungan rasio unsur alkali terhadap unsur asam, dengan kadar sulfur, sesuai persamaan (1), dimana S adalah Total Sulfur (\%) dalam DB.

Rs $($ Slagging index $)=\{(\mathrm{Fe} 2 \mathrm{O} 3+\mathrm{CaO}+\mathrm{MgO}+\mathrm{Na} 2 \mathrm{O}+\mathrm{K} 2 \mathrm{O}) / \mathrm{SiO} 2+\mathrm{A} 12 \mathrm{O} 3+\mathrm{TiO} 2\} \quad \mathrm{X} \mathrm{S}$

$\begin{array}{ll}\text { Standar nilai Potensi slagging } & \text { Nilai Rs } \\ \text { - Low } & 0.6< \\ \text { - Medium } & 0.6 \sim 2.0 \\ \text { - High } & 2.0 \sim 2.6 \\ \text { - Severe } & >2.6\end{array}$


Ika Yuliyani dkk /Jurnal Rekayasa Mesin

p-ISSN: 1411-6863, e-ISSN: 2540-7678

Vol.16|No.3|299-310|Desember|2021

b) Abu tipe lignit

Pada slagging, yang banyak berpengaruh adalah $\mathrm{CaO}$ yang merupakan unsur yang mudah menempel di dinding penghantar panas, dan $\mathrm{Na} 2 \mathrm{O}$ yang merupakan unsur yang menentukan kekuatan ikatan abu yang menempel. Tipe lignit banyak mengandung kedua unsur tersebut. Dan parameter untuk penilaian slagging pada tipe ini adalah suhu melebur abu saja. Hampir semua lignit termasuk sebagian besar batubara sub-bituminus dievaluasi berdasarkan perhitungan di bawah ini.

Rs $($ Slagging index $)=\{$ HT (Hemisphere Temp. $)+4$ X IDT (Initial Deformation Temp. $)\} / 5$

Meskipun suhu lebur abu dapat diukur dalam lingkungan oksidasi maupun reduksi., tetapi suhu pada kondisi reduksi pada umumnya menunjukkan angka yang lebih rendah dibandingkan pada kondisi oksidasi $\left(50 \sim 200^{\circ} \mathrm{C}\right)$. Hal ini terkadang dapat mempengaruhi hasil penilaian.

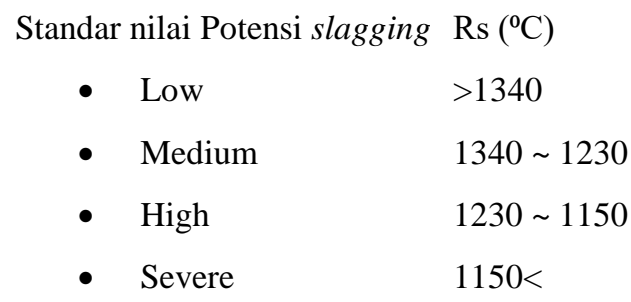

Rasio alkali dalam abu (base/acid ratio)

Rasio alkali dalam abu ditampilkan dalam persamaan berikut ini:

Rasio alkali dalam abu $=$ unsur alkali $/$ unsur asam $=(\mathrm{Fe} 2 \mathrm{O} 3+\mathrm{CaO}+\mathrm{MgO}+\mathrm{Na} 2 \mathrm{O}+\mathrm{K} 2 \mathrm{O}) /(\mathrm{SiO} 2+\mathrm{Al} 2 \mathrm{O} 3+$ $\mathrm{TiO} 2$ )

Persamaan di atas menunjukkan rasio tingkat kemungkinan pembentukan low molten-salt oleh unsur - unsur logam dalam abu (kecuali Si yang non logam) pada saat pembakaran batubara.

Bila rasio ini tinggi, maka oksida dengan titik lebur rendah dan senyawa alkali akan mudah terbentuk, menyebabkan kecenderungan slagging juga meninggi. Untuk rentang nilainya, meskipun sedikit banyak tergantung pula dari unsur unsur yang lain (persentase dari $\mathrm{Fe} 2 \mathrm{O} 3, \mathrm{CaO}, \mathrm{SiO} 2, \mathrm{Al} 2 \mathrm{O} 3$, dan lain - lain), tapi hampir semua abu menunjukkan kecenderungan suhu lebur abu yang rendah dan potensi slagging yang tinggi pada rasio $0.4 \sim 07$.

\section{Base-Acid Ratio}

Unsur pokok abu batubara dapat diklasifikasikan sebagai basa atau asam. Unsur basa terdiridaribesi, logam alkali tanah kalsium dan magnesium, dan logam alkali natrium dan kalium. Unsur asam terdiri dari silikon, aluminium dan titanium. Basa dan asam cenderung bergabung membentuk senyawa dengan suhu leleh yang lebih rendah. Proporsi relative dari unsure basa dan asam memberikan indikasi perilaku leleh dan karakteristik viskositas abu batubara. Analisis unsure digunakan untuk menghitung persen basa, persen asam dan perbandingan basadengan asam sebagai berikut: 
Ika Yuliyani dkk /Jurnal Rekayasa Mesin

p-ISSN: 1411-6863, e-ISSN: 2540-7678

Vol.16|No.3|299-310|Desember|2021

Untuk abu bituminous

$\%$ Basa $=\left(\llbracket \mathrm{Fe} \rrbracket \_2 \mathrm{O} \_3+\mathrm{CaO}+\mathrm{MgO}+\llbracket \mathrm{Na} \rrbracket \_2 \mathrm{O}+\mathrm{K} \_2 \mathrm{O}\right) \times 100 /\left(\llbracket \mathrm{SiO} \rrbracket \_2+\llbracket \mathrm{Al} \rrbracket \_2 \mathrm{O} \_3+\llbracket \mathrm{TiO} \rrbracket \_2+\llbracket \mathrm{Fe}\right.$

】_2 $\left.\mathrm{O} \_3+\mathrm{CaO}+\mathrm{MgO} \llbracket+\mathrm{Na} \rrbracket \_2 \mathrm{O}+\mathrm{K} \_2 \mathrm{O}\right)$

$\% \mathrm{Asam}=\left(\llbracket \mathrm{SiO} \rrbracket \_2+\llbracket \mathrm{Al} \rrbracket \_2 \mathrm{O} \_3+\llbracket \mathrm{TiO} \rrbracket \_2 \mathrm{~s} \times 100 /\left(\llbracket \mathrm{SiO} \rrbracket \_2+\llbracket \mathrm{Al} \rrbracket \_2 \mathrm{O} \_3+\llbracket \mathrm{TiO} \rrbracket \_2+\llbracket \mathrm{Fe} \rrbracket \_2\right.\right.$

$\mathrm{O} \_3+\mathrm{CaO}+\mathrm{MgO}$ [ $\left.+\mathrm{Na} \rrbracket \_2 \mathrm{O}+\mathrm{K} \_2 \mathrm{O}\right)$

$\mathrm{B} / \mathrm{A}$ ratio $=\left(\llbracket \mathrm{Fe} \rrbracket \_2 \mathrm{O} \_3+\mathrm{CaO}+\mathrm{MgO}+\llbracket \mathrm{Na} \rrbracket \_2 \mathrm{O}+\mathrm{K} \_2 \mathrm{O}\right) /\left(\llbracket \mathrm{SiO} \rrbracket \_2+\llbracket \mathrm{Al} \rrbracket \_2 \mathrm{O} \_3+\llbracket \mathrm{TiO} \rrbracket \_2\right)$

Indeks slag $=\mathrm{B} / \mathrm{A} \times \mathrm{S}$

Dimana:

$\mathrm{B} / \mathrm{A}=$ base-acid ratio.

$\mathrm{S}=$ berat (\%) sulfur pada dry coal basis

\subsection{Metode Evaluasi Representatif Fouling.}

Sebagaimana dijelaskan sebelumnya bahwa faktor utama yang mempengaruhi kondisi menempelnya abu adalah Na2O. Oleh karenaitu, perusahaan B \& W menentukan penilaian fouling berdasarkan persamaan di bawahini. Untuk pembagian tipe abu juga sama dengan untuk slagging.

Abu tipe bituminus $(\mathrm{CaO}+\mathrm{MgO}<\mathrm{Fe} 2 \mathrm{O} 3)$

$\mathrm{Rf}($ Fouling index $)=\{(\mathrm{Fe} 2 \mathrm{O} 3+\mathrm{CaO}+\mathrm{MgO}+\mathrm{Na} 2 \mathrm{O}+\mathrm{K} 2 \mathrm{O}) /(\mathrm{SiO} 2+\mathrm{Al} 2 \mathrm{O} 3+\mathrm{TiO} 2)\} \mathrm{X} \mathrm{Na} 2 \mathrm{O}$

Standarnilai Potensi fouling Rf

- Low $0.2<$

- Medium $0.2 \sim 0.5$

- High $0.5 \sim 1.0$

- Severe $>1.0$

Abu tipe lignit $(\mathrm{CaO}+\mathrm{MgO}>\mathrm{Fe} 2 \mathrm{O} 3), \mathrm{Rf}=$ kadar $\mathrm{Na} 2 \mathrm{O}(\%)$

Standar nilai Potensi fouling $\quad$ Rf

- Low $1.2<$

- Medium $1.2 \sim 3.0$

- High $3.0 \sim 6.0$

- Severe $>6.0$ 
Ika Yuliyani dkk /Jurnal Rekayasa Mesin p-ISSN: 1411-6863, e-ISSN: 2540-7678 Vol.16|No.3|299-310|Desember|2021

Unsur lainnya.

Selain cara - cara di atas, terdapat pula unsur-unsur lain yang juga mempengaruhi kecenderungan fouling. Diantaranya adalah $\mathrm{Na} 2 \mathrm{O}$. Unsur yang paling berpengaruh terhadap kecenderungan fouling adalah unsur alkali, terutama Na. Seperti dijelaskan di atas bahwa pengaruh $\mathrm{Na} 2 \mathrm{O}$ adalah besar. Batubara yang abunya (baik tipe lignit maupun bituminus) mengandung Na2O dengan kadar lebih dari 1 2\% (sebagian fabrikan menunjuk angka lebih dari $2 \sim 4 \%$ ) mengindikasikan memiliki kecenderungan fouling yang tinggi.

\subsection{Data Batubara}

Pada penelitian ini ada 2 jenis batu bara yang digunakan, yaitu batubara lignit dan bituminus. Berikut data hasil analisa kedua jenis batubara tersebut.

Tabel 3. Data analisis batubara 1

\begin{tabular}{|c|c|c|c|c|c|}
\hline \multirow{2}{*}{ Parameter } & \multirow{2}{*}{ Units } & \multicolumn{4}{|c|}{ Results (Basis) } \\
\hline & & ARB & ADB & DB & DAFB \\
\hline \multicolumn{6}{|l|}{ Proximate Analysis } \\
\hline Total Moisture & $\%$ wt & 34.20 & - & - & - \\
\hline Moisture in analysis & $\% \mathrm{wt}$ & - & 19.33 & - & - \\
\hline Ash Content & $\%$ wt & 1.79 & 2.19 & 2.71 & - \\
\hline Volatile Matter & $\%$ wt & 32.00 & 39.23 & 48.63 & 49.99 \\
\hline Fixed Carbon & $\% \mathrm{wt}$ & 32.01 & 39.25 & 48.66 & 50.01 \\
\hline Total sulfur & $\% \mathrm{wt}$ & 0.09 & 0.11 & 0.14 & 0.14 \\
\hline Gross Calorific Value & $\mathrm{Kcal} / \mathrm{Kg}$ & 4373 & 5361 & 6646 & 6831 \\
\hline \multicolumn{6}{|l|}{ Ultimate Analysis } \\
\hline Total Moisture & $\%$ wt & 34.20 & - & - & - \\
\hline Moisture in analysis & $\%$ wt & - & 19.33 & - & - \\
\hline Ash Content & $\%$ wt & 1.79 & 2.19 & 2.71 & - \\
\hline Sulfur & $\%$ wt & 0.09 & 0.11 & 0.14 & 0.14 \\
\hline Hydrogen & $\% \mathrm{wt}$ & 3.85 & 4.72 & 5.85 & 6.01 \\
\hline Carbon & $\% \mathrm{wt}$ & 46.93 & 57.54 & 71.33 & 73.32 \\
\hline Nitrogen & $\% \mathrm{wt}$ & 0.64 & 0.79 & 0.98 & 1.01 \\
\hline Oxygen & $\% \mathrm{wt}$ & 12.50 & 15.32 & 18.99 & 19.52 \\
\hline \multicolumn{6}{|l|}{ Ash Analysis } \\
\hline $\mathrm{SiO}_{2}$ & $\%$ wt & \multicolumn{4}{|c|}{40,81} \\
\hline$\overline{\mathrm{Al}_{2} \mathrm{O}_{3}}$ & $\%$ wt & \multicolumn{4}{|c|}{5,97} \\
\hline $\mathrm{Fe}_{2} \mathrm{O}_{3}$ & $\% \mathrm{wt}$ & \multicolumn{4}{|c|}{13,40} \\
\hline $\mathrm{CaO}$ & $\%$ wt & \multicolumn{4}{|c|}{17,19} \\
\hline $\mathrm{MgO}$ & $\% \mathrm{wt}$ & \multicolumn{4}{|c|}{10,48} \\
\hline $\mathrm{K}_{2} \mathrm{O}$ & $\% \mathrm{wt}$ & \multicolumn{4}{|c|}{0,15} \\
\hline
\end{tabular}


Ika Yuliyani dkk /Jurnal Rekayasa Mesin p-ISSN: 1411-6863, e-ISSN: 2540-7678 Vol.16|No.3|299-310|Desember|2021

\begin{tabular}{|c|c|c|c|c|c|}
\hline \multirow{2}{*}{ Parameter } & \multirow{2}{*}{ Units } & \multicolumn{4}{|c|}{ Results (Basis) } \\
\hline & & ARB & ADB & DB & $\overline{\text { DAFB }}$ \\
\hline $\mathrm{Na}_{2} \mathrm{O}$ & $\%$ wt & \multicolumn{4}{|c|}{0,06} \\
\hline $\mathrm{MnO}_{2}$ & $\% \mathrm{wt}$ & \multicolumn{4}{|c|}{0,29} \\
\hline $\mathrm{TiO}_{2}$ & $\%$ wt & \multicolumn{4}{|c|}{1,17} \\
\hline $\mathrm{P}_{2} \mathrm{O}_{5}$ & $\%$ wt & \multicolumn{4}{|c|}{0,54} \\
\hline $\mathrm{SO}_{3}$ & $\%$ wt & \multicolumn{4}{|c|}{9,10} \\
\hline Undetermined & $\%$ wt & \multicolumn{4}{|c|}{0,48} \\
\hline Ash classified & & \multicolumn{4}{|c|}{ Lignite } \\
\hline Ash Fusion Temperature & & \multicolumn{2}{|c|}{ Reducing } & \multicolumn{2}{|c|}{ Oxidizing } \\
\hline initial deformation temperature (IDT) & ${ }^{\circ} \mathrm{C}$ & \multicolumn{2}{|c|}{1230} & \multicolumn{2}{|c|}{1270} \\
\hline softening temperature (ST) & ${ }^{\circ} \mathrm{C}$ & \multicolumn{2}{|c|}{1240} & \multicolumn{2}{|c|}{1280} \\
\hline hemispherical temperature (HT) & ${ }^{\circ} \mathrm{C}$ & \multicolumn{2}{|c|}{1250} & \multicolumn{2}{|c|}{1290} \\
\hline fluid temperatur (FT) & ${ }^{\circ} \mathrm{C}$ & \multicolumn{2}{|c|}{1260} & \multicolumn{2}{|c|}{1300} \\
\hline ARB: As-Received Basis & \multicolumn{5}{|c|}{ DB: Dry Basis } \\
\hline ADB: As-Determined Basis & \multicolumn{5}{|c|}{ DAFB: Dry Ash-free Basis } \\
\hline
\end{tabular}

Tabel 4. Data analisis batubara 2

\begin{tabular}{|l|c|c|c|c|c|}
\hline \multirow{2}{*}{ Parameter } & \multirow{2}{*}{ Units } & \multicolumn{4}{c|}{ Results (Basis) } \\
\cline { 4 - 6 } & & ARB & ADB & DB & DAFB \\
\hline Proximate Analysis & & & & & \\
\hline Total Moisture & $\% \mathrm{wt}$ & 27,51 & - & - & - \\
\hline Moisture in analysis & $\% \mathrm{wt}$ & - & 12,99 & - & - \\
\hline Ash Content & $\% \mathrm{wt}$ & 5,44 & 6,53 & 7,50 & - \\
\hline Volatile Matter & $\% \mathrm{wt}$ & 29,3 & 35,17 & 40,42 & 43,7 \\
\hline Fixed Carbon & $\% \mathrm{wt}$ & 37,75 & 45,31 & 52,08 & 56,30 \\
\hline Total sulfur & $\% \mathrm{wt}$ & 0,44 & 0,53 & 0,61 & 0,66 \\
\hline Gross Calorific Value & Kcal/Kg & 5000 & 6002 & 6898 & 7458 \\
\hline Ultimate Analysis & & & & & \\
\hline Total Moisture & $\% \mathrm{wt}$ & 27,51 & - & - & - \\
\hline Moisture in analysis & $\% \mathrm{wt}$ & - & 12,99 & - & - \\
\hline Ash Content & $\% \mathrm{wt}$ & 5,44 & 6,53 & 7,50 & - \\
\hline Sulfur & $\% \mathrm{wt}$ & 0,44 & 0,53 & 0,61 & 0,66 \\
\hline Hydrogen & $\% \mathrm{wt}$ & 4,17 & 5,01 & 5,76 & 6,23 \\
\hline Carbon & $\% \mathrm{wt}$ & 49,53 & 59,45 & 68,33 & 73,87 \\
\hline Nitrogen & $\% \mathrm{wt}$ & 0,84 & 1,01 & 1,16 & 1,25 \\
\hline Oxygen & $\% \mathrm{wt}$ & 12,07 & 14,48 & 16,64 & 17,99 \\
\hline Ash Analysis & & & & & \\
\hline SiO ${ }_{2}$ & $\% \mathrm{wt}$ & & & 53,38 & \\
\hline
\end{tabular}


Ika Yuliyani dkk /Jurnal Rekayasa Mesin p-ISSN: 1411-6863, e-ISSN: 2540-7678 Vol.16|No.3|299-310|Desember|2021

\begin{tabular}{|c|c|c|c|c|c|}
\hline \multirow{2}{*}{ Parameter } & \multirow{2}{*}{ Units } & \multicolumn{4}{|c|}{ Results (Basis) } \\
\hline & & ARB & ADB & $\mathrm{DB}$ & DAFB \\
\hline $\mathrm{Al}_{2} \mathrm{O}_{3}$ & $\%$ wt & \multicolumn{4}{|c|}{31,46} \\
\hline $\mathrm{Fe}_{2} \mathrm{O}_{3}$ & $\%$ wt & \multicolumn{4}{|c|}{4,62} \\
\hline $\mathrm{CaO}$ & $\%$ wt & \multicolumn{4}{|c|}{1,04} \\
\hline $\mathrm{MgO}$ & \%wt & \multicolumn{4}{|c|}{1,84} \\
\hline $\mathrm{K}_{2} \mathrm{O}$ & $\%$ wt & \multicolumn{4}{|c|}{0,67} \\
\hline $\mathrm{Na}_{2} \mathrm{O}$ & $\%$ wt & \multicolumn{4}{|c|}{0,88} \\
\hline $\mathrm{MnO}_{2}$ & $\%$ wt & \multicolumn{4}{|c|}{0,05} \\
\hline $\mathrm{TiO}_{2}$ & $\%$ wt & \multicolumn{4}{|c|}{1,19} \\
\hline $\mathrm{P}_{2} \mathrm{O}_{5}$ & $\%$ wt & \multicolumn{4}{|c|}{0,40} \\
\hline $\mathrm{SO}_{3}$ & $\%$ wt & \multicolumn{4}{|c|}{4,03} \\
\hline undetermined & $\%$ wt & \multicolumn{4}{|c|}{0,44} \\
\hline Ash classified & & \multicolumn{4}{|c|}{ bituminus } \\
\hline Ash Fusion Temperature & & \multicolumn{2}{|c|}{ Reducing } & \multicolumn{2}{|c|}{ Oxidizing } \\
\hline initial deformation temperature (IDT) & ${ }^{\circ} \mathrm{C}$ & \multicolumn{2}{|c|}{1450} & \multicolumn{2}{|c|}{+1450} \\
\hline softening temperature (ST) & ${ }^{\circ} \mathrm{C}$ & \multicolumn{2}{|c|}{+1450} & \multicolumn{2}{|c|}{+1451} \\
\hline hemispherical temperature (HT) & ${ }^{\circ} \mathrm{C}$ & \multicolumn{2}{|c|}{+1451} & \multicolumn{2}{|c|}{+1452} \\
\hline fluid temperatur (FT) & ${ }^{\circ} \mathrm{C}$ & \multicolumn{2}{|c|}{+1452} & \multicolumn{2}{|c|}{+1453} \\
\hline ARB: As-Received Basis & \multicolumn{5}{|c|}{ DB: Dry Basis } \\
\hline ADB: As-Determined Basis & \multicolumn{5}{|c|}{ DAFB: Dry Ash-free Basis } \\
\hline
\end{tabular}

\section{Hasil dan pembahasan}

\subsection{Indeks slagging pada abu lignit dan bituminous.}

Hasil dari indeks slagging dan fouling atau potensi pembentukan slagging dan fouling dapat diketahui berdasarkan metode perhitunga-perhitungan yang sesuai dengan jenis batubara yang digunakan pada pembangkit listrik tenaga uap tersebut. Apakah batubara tersebut menggunakan jenis bituminus, lignit atau sub bituminum. Indeks slagging dapat diketahui melalui beberapa parameter, seperti parameter base-acid ratio (slagging factor) untuk abu bituminus dan ash fusion temperature untuk jenis abu lignit. Nilai indeks slagging pada batubara lignit dapat dilihat pada Tabel 4.1. dibawah ini.

Tabel 5. Hasil perhitungan slagging lignit

\begin{tabular}{ccc}
\hline Jenis abu Batubara & Indeks slagging & Slagging Propensity \\
\hline lignit & 1234 & Sedang \\
lignit & 1244 & Sedang \\
lignit & 1450 & Rendah \\
lignit & 1450 & Rendah \\
lignit & 1450 & Rendah \\
lignit & 1450 & Rendah \\
lignit & 1450 & Rendah \\
\hline
\end{tabular}


Ika Yuliyani dkk /Jurnal Rekayasa Mesin p-ISSN: 1411-6863, e-ISSN: 2540-7678 Vol.16|No.3|299-310|Desember|2021

Pada Tabel 5 ada 2 hasil nilai indeks slagging yang diperoleh selama pengamatan dari tanggal 1 - 23 Juni 2019 , yaitu memiliki nilai indeks slagging dengan kategori sedang untuk 2 data pertama dan nilai indeks rendah pada hasil berikutnya dengan jumlah data 5. dua data yang menunjukan bahwa nilai indeks slagging yang tinggi pada abu jenis lignit terjadi pada nilai ash fusion temperature yang cukup rendah $1234^{\circ} \mathrm{C}$ dan $1244^{\circ} \mathrm{C}$ sedangkan nilai ash fusion temperatur data lainnya adalah 1450VC. Hal ini menunjukkan bahwa meskipun batubara yang digunakan jenis lignit akan tetapi nilai indeks slaggingnya sebagian besar masih dikategorikan rendah.

Tabel 6. Hasil perhitungan slagging bituminus

\begin{tabular}{lll}
\hline Jenis abu & Indeks slagging & Slagging Propensity \\
Batubara & & rendah \\
Bituminus & 0,06 & rendah \\
Bituminus & 0,13 & rendah \\
Bituminus & 0,06 & rendah \\
Bituminus & 0,07 & rendah \\
Bituminus & 0,09 & rendah \\
Bituminus & 0,07 & rendah \\
Bituminus & 0,05 & rendah \\
Bituminus & 0,08 & rendah \\
Bituminus & 0,08 & rendah \\
\hline
\end{tabular}

Hasil metode perhitungan yang ditunjukkan pada Tabel 6 nilai indeks slagging pada abu bituminous memiliki kecenderungan yang rendah dengan nilai indeks basa-asam rasio berkisar dari 0,05 sampai 0,13. Namun, hasil yang ditampilkan pada Tabel 5. dan Tabel 6 agak sulit untuk membandingkan potensi pembentukan slagging pada dua jenis abu bituminus dan lignit, karena keduanya menggunakan metode perhitungan indeks mengunakan dengan parameter yang berbeda. Untuk mengatasinya maka perhitungan harus ada indeks perhitungan slagging dengan menggunakan parameter viskositas untuk dapat membandingkan dua jenis abu yang berbeda.

Tabel 7. Hasil perhitungan slagging (viskositas)

\begin{tabular}{ccccccc}
\hline Jenis abu & $\mathbf{T}_{\mathbf{2 5 0}}$ & $\mathbf{T}_{\mathbf{1 0 0 0}}$ & $\mathbf{T}_{\mathbf{2 0 0 0}}$ & $\mathbf{f}_{\mathbf{s}}$ & Indek & Slagging \\
\hline lignit & 1289,7 & 1004,84 & 1100,32 & 1,4 & 1,3 & high \\
lignit & 1233,9 & 992,61 & 1076,4 & 1,3 & 1,25 & high \\
lignit & 1249,0 & 1088,92 & 1149,7 & 1,8 & 0,69 & medium \\
lignit & 1206,6 & 1055,8 & 1113,2 & 1,4 & 0,85 & medium \\
lignit & 1210,2 & 1064,1 & 1120,5 & 1,5 & 0,77 & medium \\
lignit & 1201,2 & 1056,1 & 1111,6 & 1,4 & 0,82 & medium \\
lignit & 1197,3 & 1053,7 & 1108,7 & 1,4 & 0,81 & medium \\
\hline
\end{tabular}


Ika Yuliyani dkk /Jurnal Rekayasa Mesin

p-ISSN: 1411-6863, e-ISSN: 2540-7678

Vol.16|No.3|299-310|Desember|2021

Tabel 8. Hasil perhitungan indeks slagging (viscositas)

\begin{tabular}{ccccccc}
\hline Jenis abu & $\mathbf{T}_{\mathbf{2 5 0}}$ & $\mathbf{T}_{\mathbf{1 0 0 0}}$ & $\mathbf{T}_{\mathbf{2 0 0 0}}$ & $\mathbf{\mathbf { f } _ { \mathbf { s } }}$ & Indeks & Slagging \\
\hline bituminus & 1268,8 & 1101,9 & 1165,0 & 1,8 & 0,68 & medium \\
bituminus & 1609,8 & 1212,9 & 1342,1 & 1,8 & 0,51 & medium \\
bituminus & 1237,9 & 1087,6 & 1145,1 & 1,9 & 0,66 & medium \\
bituminus & 1253,6 & 1092,4 & 1153,5 & 1,8 & 0,77 & medium \\
bituminus & 1240,9 & 1078,3 & 1139,8 & 1,6 & 0,79 & medium \\
bituminus & 1237,3 & 1074,4 & 1135,9 & 1,6 & 0,79 & medium \\
bituminus & 1266,9 & 1100,1 & 1163,2 & 1,5 & 0,77 & medium \\
bituminus & 1224,7 & 1064,7 & 1125,2 & 1,5 & 0,83 & medium \\
bituminus & 1211,0 & 1056,7 & 1115,3 & 1,5 & 0,80 & medium \\
\hline
\end{tabular}

Dari data yang ditunjukkan pada Tabel 7 dan Tabel 8 diperoleh hasil bahwa rata-rata index slagging berdasarkan perhitungan viscositas abu lignit lebih tinggi jika dibandingkan dengan abu bituminus, hasil ini sama dengan yang ditunjukan oleh perbandingan hasil dari perhitungan menggunakan parameter basa-asam rasio dengan ash fusion temperature yang ditunjukkan pada Tabel 5 dan Tabel 6.

\section{Kesimpulan}

Hasil dari penelitian ini diperoleh beberapa kesimpulan adalah potensi pembentukan slagging untuk batubara dengan jenis abu bituminous sangat dipengaruhi oleh adanya kandungan unsur Fe2O3, dan pada batubara jenis abu lignit dipengaruhi oleh adanya unsur $\mathrm{CaO}$ dan $\mathrm{MgO}$. Potensi pembentukan fouling pada batubara dengan jenis bituminus dan lignit adalah adanya unsur $\mathrm{Na2O}$. Batubara dengan jenis abu lignit cenderung memiliki indeks nilai potensi pembentukan slagging dan fouling yang lebih tinggi dibandingkan dengan batubara dengan jenis abu bituminus.

\section{DaftarPustaka}

[1] K. rayaprolu, Boilers for power and prosses, U.S.A.: CRC Press, 2009..

[2] Babcock and Wilcox, Steam its generation and use, 41 ed., J. B. K. a. S. C. Stultz, Ed., Barberton, ohio: Babcock and Wilcox, 2005.

[3] D. S. rao, Minerals and coal prosses calculation, UK: CRC Press, 2016.

[4] J. G. Speight, Handbook of coal analysis, 2 ed., vol. 182, new jersey: Wiley, 2015.

[5] Nadiyatul Fadhilla, Analisis Pengaruh Terbentuknya Slagging dan Fouling Terhadap Efisiensi Boiler pada Boiler Supercritical; Jurnal Mekanik Terapan vol 01 no 01 (2020),

[6] N. Amaliyah dan M. Fachry, "Analisis Komposisi Batubara Mutu Rendah Terhadap Pembentukan Slagging dan Fouling Pada Boiler," Jurnal Energy, 2011.

[7] F. G. Sumarno, W. dan O. I. Aditya, "Fauling dan Pengaruhnya Pada Final Secondary Superheate PLTU Tanjung Jati B Unit 2,” Jurnal Energi Jurusan Teknik Mesin PNS, vol. 10 No 1, 2014

[8] H. Speliethoff, "Characterizition of Slagging and Fouling in Biomass Combustion Bioslag," Energi Technology TU Delft, 2000.

[9] Cahyadi, PLTU batubara supercritikal yang efisien, Tanggerang selatan: BPPT , 2015 
Ika Yuliyani dkk /Jurnal Rekayasa Mesin

p-ISSN: 1411-6863, e-ISSN: 2540-7678

Vol.16|No.3|299-310|Desember|2021

[10] Wahyuno, dkk.(2014).Fouling dan Pengaruhnya Pada Final Secondary Superheater PLTU TanjungJati B unit 2 . Semarang. Politeknik Negeri Semarang; 2014.

[11] J. li, "effect of coal blending on ash fouling and slagging in pulverized coal fired supercritical (SC) and ultrasupercritical (UC) power planr," thesis university of western australia, australia, 2016..

[12] Winda Ayu Prameswari, Analisa pembentukan slagging dan fouling pembakaran batubara pada Boiler B0201B Pabrik 3 unit UBB di PT. Petrokimia Gresik; 2017

[13] D. Zhang. (2013).Ash fouling, deposition and slagging in ultra -supercritical coal power plants Australia :University of Science and Technology Liaoning, China and The University of Western Australia; 2013

[14] Awad, M. M. (2011). Fouling of heat transfer surfaces. Chemical Engineering \& Technology, 10(1),113-125.

[15] Wu Xiaojiang. (2014). Inhibition of lignite ash slagging and fouling upon the use of a silica-based additive in an industrial pulverised coal-fired boiler. Department of Chemical Engineering, Monash University, Clayton, Victoria 3800, Australia . 